Himat Vaghadia BSC MHSC MBES ERCFC FFARCS, Martin T. Schechter MD PH D,

Samuel B. Sheps MD FRCPC, Leonard C. Jenkins BA MD CM FRCPC

\title{
Evaluation of a postocclusive reactive circulatory hyperaemia (PORCH) test for the assessment of ulnar collateral circulation
}

\begin{abstract}
This prospective double-blind study compared Doppler assessment of the uinar coliateral circulation with the Allen's test and a postocclusive reactive circulatory hyperaemia (PORCH) test in 144 patients ( 288 hands). The PORCH test involves inflation of a blood pressure cuff on the upper arm to a supra systolic $(+50 \mathrm{mmHg})$ pressure for (wo minutes. Prior to cuff deflation. bath radial and ulnar arteries are occluded at the wrist; the cuff is then deflated and a 15 -second period allowed so as to restore blood fow down to the wrist. Ulnar artery compression is now released and the time to revascularization measured. Fifty-eight per cent of hands with an abnormal Allen's test had a normal uinar collateral circulation. Results of Allen's test were not significantly affected by patients' sex or smoking status ( $p>0.1$ ) but there was a significant difference $(p=0.001)$ in the false positive rates between patients over 40 years of age $(0.2)$ and those under 40 years of age $(0.03)$. Results of the PORCH test were not significantly affected by patients' age, sex or smoking status ( $p>0.1$ ). With a revascularisation time of 19 sec as a "cut off" for ulnar abnormality the PORCH test, unilike the Allen's test, was perfectly predictive of an abnormal ulnar collateral circulation and had no false positives.
\end{abstract}

\section{Key words}

ARTERIES: radial, ulnar, Allen's test, postocclusive reactive circulatory hyperaemia (PORCH) test; EQUIPMENT: Doppler ultrasonic velocity detector; MONITORING: blood pressure.

From the Department of Anaesthesia, Vancouver General Hospital and Department of Health Care and Epidemiology (MTS, SBS), The University of British Columbia, Vancouver, British Columbia.

Presented in part at the 1987 Annual Meeting of the Canadian Anaesthetists' Society, Calgary, Alberta.

Address correspondence 10: Dr. H. Vaghadia, Department of Anaesthesia, Faculty of Medicine. The University of British Columbia, Room 3200, 910 West 10th Avenue, Vancouver, B.C. V5Z 4E3.
A modified Allen's test has become established as a simple method for assessing collateral ulnar arterial flow prior to cannulation of the radial artery. ${ }^{1-3}$ Although in clinical practice the decision to cannulate a radial artery is often based on the results of an Allen's test, this test has been shown to have a high incidence of false positives. ${ }^{4.5}$ Unfortunately a systematic study assessing the usefulness of the Allen's test in evaluating ulnar collateral circulation has not been published. Preliminary observations on capillary refilling led to the development of a postocclusive reactive circulatory hyperaemia (PORCH) test. Subsequently, patients with abnormal Allen's tests were found to have brisk ulnar refilling with the PORCH test.

The present prospective double-blind study was designed to compare the results of Doppler examination of the ulnar collateral circulation with Allen's test and the PORCH test. The purpose of the study was to assess the usefulncss of the latter two tests in identifying patients with an abnormal ulnar collateral circulation prior to radial artery cannulation. In addition, the effects of age, sex and smoking on the results of the two tests were examined.

\section{Methods}

\section{Study design}

One hundred and forty-four consecutive hospitalized patients ( 288 hands) were studied. Inclusion criteria were that radial artery cannulation might be required and that there had been no previous radial artery cannulation in either hand. Exclusion criteria were a history of previous vascular invasive procedure(s) in either upper limb, or refusal of consent. Informed consent was obtained from each patient. All patients were examined supine with their head and shoulders comfortably elevated and their hands by their sides. Each patient was initially assessed by one investigator (HV) using Doppler ultrasound which was 
taken as the "gold standard" for an abnormal ulnar collateral circulation. Subsequently, two specially trained medical student interns (MSI) performed a modified Allen's test (MSI-A) followed by the $\mathrm{PORCH}$ test (MSI-B). The test sequence was identical in all patients with an interval of five minutes being allowed between tests. None of the investigators or the patients was aware of the results of the other tests.

\section{Doppler srudies}

A portable Doppler ultrasonic velocity detector (Parks Electronics Corporation, Model 804) set at a maximum sensitivity was used to perform two tests in all patients: (a) continuity of the palmar arch was assessed by noting the response of arterial velocity signal in the ulnar artery at the wrist to compression of the radial artery. Failure of the arterial velocity in the ulnar artery to increase during radial artery compression was interpreted as indicative of a lack of continuity between the radial and ulnar circulations and hence an abnormal ulnar collateral circulation, ${ }^{6}$ (b) the superficial palmar arch was identified using the method described by Mozersky et al. ${ }^{7}$ Complete disappearance of the arterial velocity signal over the arch during radial artery compression was interpreted as indicating an incomplete arch with an abnormal ulnar circulation. ${ }^{7}$ Patients classified as abnormal by the above. Iwo tests were further assessed by a third test as described by Little et al. ${ }^{8}$ Pulsatile flow was located in the interdigital artery of the first interdigital cleft (between index and middle fingers) and the effects of radial artery compression noted. Loss of pulsatile tlow during radia] artery compression or failure to detect flow in the absence of such compression suggested absence of ulnar arterial flow to that vessel and was considered abnormal. ${ }^{8}$

Those patients who satisfied all three criteria for abnormality were classified as having an abnormal ulnar collateral circulation. The remainder were classifjed as normal.

\section{Allen's test}

MSI-A was assigned exclusively to perform a modified Allen's test in all patients according to the technique described by Kaye. ${ }^{9}$ The time from ulnar artery release to the appearance of a blush on the volar and distal aspects of the thumb, index and middle fingers, extending from the middle digital crease to the tips was noted with a view to maintaining consistency ${ }^{10}$ Reproducibility and reliability of the test were assessed in a subgroup of 30 (25 normal; 5 abnormal) prospectivcly selectcd patients. In each patient, MSI-A's results were compared with one investigator (HV) when both performed Allen's test blindly.

In accordance with previous studies ${ }^{11,12}$ and recom- mendations, ${ }^{13}$ patients with a revascularization time of 15 sec or more were classitied as having an abnormal ulnar collateral circulation by Allen's test.

\section{Postocclusive reactive circulatory hyperaemia (PORCH) test}

MSI-B exclusively performed the PORCH test in all patients. Intense reactive hyperaemia was stimulated by application of a blood pressure cuff to the upper arm, with a suprasystolic $(+50 \mathrm{mmHg}$ ) pressure for two minutes. Prior to release of cuff compression (cartied out by the patient) both radial and ulnar arteries were occluded at the wrist. A period of 15 seconds after cuff release was allowed in order to restore blood flow down to the wrist. At the end of this interval ulnar artery compression was released and the time to revascularization was measured using the same endpoint as described for Allen's test. Test reproducibility and reliability were assessed in the same subgroup of 30 patients as for Allen's test. In each patient, MSI-B's results were compared with investigator $\mathrm{HV}$ when both performed the PORCH test blindly

To facilitate comparison with Allen's test, patients with a revascularization time of 15 seconds or more with the PORCH test werc classified as having an abnormal ulnar collateral circulation by the PORCH test.

\section{Analysis}

Both Allen's test and the PORCH test were evaluated by applying current criteria for the assessment of diagnostic tests: sensitivity, specificity, positive and negative predictive values, positive and negative likelihood ratios (LR+ and LR-) and accuracy using Doppler studies as the reference. ${ }^{14.15}$ The effects of age, sex and smoking on both tests were assessed by means of the Chi-square test as well as Fisher's exact test where indicated. Differences were considered significant when the probability (p) value was $<0.05$.

Reliability and reproducibility of Allen's test and the PORCH test were assessed by computing the Kappa statistic. ${ }^{16}$

\section{Results}

\section{Clinical findings}

Sixty males (mean age 43.7 years, range 21 to 100 years) and 84 females (mean age 34.6 years, range 19 to 74 years) were studied. Seven males were judged to have an abnormal ulnar collateral circulation as judged by the Doppler studies. The abnormality was present bilaterally (i.e., 14 hands) and all seven males were non-smokers. Their clinical details are summarized in Table I. No 
TABLE I Clinical characteristics of seven patients with an abnomal ulnar collatera] circulation

\begin{tabular}{|c|c|c|c|}
\hline Patient No. & Age & Sex & Principal diagnosis \\
\hline 1 & 82 & $M$ & Pneumonia \\
\hline 2 & 100 & $\mathrm{M}$ & Pneumonia \\
\hline 3 & 88 & $\mathbf{M}$ & $\begin{array}{l}\text { Reinal tubular acidosis; } \\
\text { hyperkalacmia }\end{array}$ \\
\hline 4 & 78 & $\mathrm{M}$ & $\begin{array}{l}\text { Didbetes mellitus; } \\
\text { peripheral vascular disease; } \\
\text { amputation of left toe }\end{array}$ \\
\hline 5 & 62 & M & Chronic pericistelitis \\
\hline 6 & 70 & $M$ & Leukaemia \\
\hline 7 & 57 & $\mathbf{M}$ & Angind \\
\hline
\end{tabular}

female patients were judged to have an abnormal ulnar circulation.

Among the remaining 137 patients judged to have a normal ulnar collateral circulation there were 19 smokers (7 male, 12 female). The mean number of cigarettes smoked per day was 16 (range 10-40 cigarettes per day). A history of diabetes mellitus, hypertension or vascular disease in the arms (e.g., Raynaud's cisease or thromboangitis obliterans) was not abtained in any patient with a normal or abnormal collateral circulation.

\section{Allen's test}

Results for Allen's test in 137 patients ( 274 hands) with a nomal ulnar collateral circulation demonstrated that the mean time for revascularization was $7.1 \mathrm{sec}(\mathrm{SD} \pm 5.7$ sec); 18 patients had revascularization times in excess of $15 \mathrm{sec}$. All patients with an abnormal ulnar collateral circulation had revascularization times in excess of $45 \mathrm{sec}$ with Allen's test.
Table II summarizes the results of 288 Allen's tests when compared to the ultrasound test.

The false positive rates for Allen's tests were not significantly different between smokers and non-smokers $\left(x^{2}=1.98, p=0.15 ; p\right.$, Fisher's exact test $\left.=0.15\right)$ or between men and women $\left(\chi^{2}=0.012, p=0.9 ; p\right.$, Fisher's test $=0,4$ ). There was, however, a significant difference between those over 40 years and those under 40 years $\left(x^{2}=15.9 ; p=0.006 ; p\right.$, Fisher's test $\left.=0.0013\right)$. The false positive rate was 0.03 for those under 40 years compared to 0.2 for those over 40 years. The Kappa statistic for Allen's test was 1.0 .

\section{The PORCH test}

Results for the PORCH test in all patients with a normal ulnar collateral circulation demonstrated that the mean time for revascularization was $5.9 \mathrm{sec}(S D \pm 2.3 \mathrm{sec})$ with results being less scuttered than Allen's test (range 2 to 18 sec)

Table III summarizes the results of $288 \mathrm{PORCH}$ tests when compared to Doppler ultrasound.

There was no significant difference in the false positive rates with the PORCH test when compared between smokers and non-smokers $\left(x^{2}=0.2, p=0.6 ; p\right.$, Fisher's test $=0.9)$; between men and women $\left(\chi^{2}=0.16, p=\right.$ $0.69 ; p$, Fisher's test $=0.37)$; or between those over 40 years and those under 40 years $\left(x^{2}=0.01, p=0.9 ; p\right.$, Fisher's test $=0,39$ ). The Kappa statistic for the PORCH test was 1.0

\section{Effect of changing revascularization time on test performance}

Table IV summarizes the change in perfornance of both

TABLE II Comparison of Allen's test with Doppler ultrasound

\begin{tabular}{|c|c|c|c|c|}
\hline & & \multicolumn{3}{|c|}{$\begin{array}{l}\text { Ulnar collateral circulation as assessed by Doppler } \\
\text { ultrasound }\end{array}$} \\
\hline & & Abnormal & Normal & Total \\
\hline \multirow{3}{*}{$\begin{array}{l}\text { Ulnar collateral } \\
\text { circulation as } \\
\text { assessed by } \\
\text { Allen's test }\end{array}$} & $\begin{array}{l}\text { Abnomal } \\
(>15 \text { sec })\end{array}$ & 14 & 19 & 33 \\
\hline & $\begin{array}{l}\text { Normal } \\
\quad(<15 \text { sec })\end{array}$ & 0 & 255 & 255 \\
\hline & & 14 & 274 & 288 \\
\hline
\end{tabular}

Sensitivity $=14 / 14=1.0 ;$ specificity $=255 / 274=0.93$; positive predictive value $=14 / 33=$ 0.42 ; negative predictive value $=255 / 222=1.0 ;(L R+)^{*}=$ sensitivily $/ 1-$ specificity $=$ $1 / 0.07=14.2 ;(L R-)^{*}=1-$ sensitivity/specificity $=0 / 0.93=0 ;$ accuracy $=269 / 288=$ 0.93 ; prevalence $=14 / 288=0.04 \mathrm{~B} .{ }^{*} \mathrm{LR}+=$ positive likelihood ratio; $L R-=$ negative likelihood ratio. ${ }^{14,15}$ 
TABLE II Comparison of PORCH test with Doppler ultrasound

\begin{tabular}{|c|c|c|c|c|}
\hline & & \multicolumn{3}{|c|}{$\begin{array}{l}\text { Ulnar collateral circulation as assessed by Doppler } \\
\text { uitrasound }\end{array}$} \\
\hline & & Abnormal & Normal & Total \\
\hline \multirow{3}{*}{$\begin{array}{l}\text { Ulnar collateral } \\
\text { circulation as } \\
\text { assessed by } \\
\text { PORCH test }\end{array}$} & $\begin{array}{l}\text { Abnormal } \\
\quad(>15 \mathrm{sec})\end{array}$ & 14 & 2 & 16 \\
\hline & $\begin{array}{l}\text { Normal } \\
\quad(<15 \mathrm{sec})\end{array}$ & 0 & 272 & 272 \\
\hline & & 14 & 274 & 288 \\
\hline
\end{tabular}

Scnsitivity $=1.0 ;$ specificity $=0.99 ;$ positive predictive value $=0.87 ;$ negative predictive value $=1.0 ;(L R+)^{*}=100 ;(L R-)=0$; accuracy $=0.99$; prevalence $=0.048$.

*LR+ = positive likelihood ratio; LR - = negative likelihood ratio. ${ }^{14,15}$

tests when three different revascularization times are used as the "cut off" between patients with a normal and those with an abnormal ulnar collateral circulation. Perfor. mance of Allen's test changed minimally with longer revascularization times whereas that of the PORCH test increased and approached the ultrasound test at a time of $19 \mathrm{sec}$ (positive predictive value of 1.0 ). The PORCH test also performed better than Allen's test at all three revascularization times.

\section{Discussion}

The choice of a suitable test for the assessment of circulatory dynamics in the hand is obviously difficult. It would be hard to justify routine arteriography with its attendant risks. In addition, arteringrams have the shortcoming of producing a static picture which may well conceal the dynamics of the circulation. ${ }^{B}$ Furthermore, controlled studies have confirmed the superiority of Doppler ultrasound over arteriography for the assessment of circulatory dynamies in arteries that are identical in size to those encountered in the hand. ${ }^{17-20}$
In the present study, the decision to use Doppler ultrasound as the "gold standard" was based upon previous clinical, ${ }^{6}$ anatomical ${ }^{21}$ and arteriographic studies. ${ }^{20}$ The reliability of Doppler ultrasound for identifying patients with an abnormal ulnar collateral circulation has already been demonstrated by Kamienski, ${ }^{6}$ Mozersky ${ }^{7}$ and Bedford. ${ }^{13}$ Furthermore, when ischaemic complications follow radial artery cannulation they usually affect the index finger, thumb or thenar area. ${ }^{4,11,22}$ These clinical reports correlate well with anatomical studies by Coleman $^{21}$ who demonstrated complete dependence of the first interdigital artery upon the radial artery for its blood supply in 2.2 per cent of 265 hands. In addition, Little et al. ${ }^{8}$ also demonstrated that radial artery compression abolished blood flow in the first interdigital artery in 3.1 per cent of subjects. Thus, an acceptable test should also take into consideration the assessment of blood flow in the first interdigital artery and evaluate its dependence upon the radial artery - this was performed in the current study. The performance of three different tests with Doppler ultrasound probably increased its reliability and

TABLE IV Effect of a change in revascularization time on the performantce of Allen's test and the PORCH test.

\begin{tabular}{|c|c|c|c|c|c|c|}
\hline \multirow{2}{*}{$\begin{array}{l}\text { Revascularization } \\
\text { time (sec) }\end{array}$} & \multicolumn{3}{|c|}{ Allen's Test } & \multicolumn{3}{|c|}{ PORCH test } \\
\hline & $\mu$ & 15 & 19 & $I I$ & 15 & 19 \\
\hline Șcnșitivity & 1.0 & 1.0 & 1.0 & 1.0 & 1.0 & 1.0 \\
\hline Specificity & 0.85 & 0.93 & 0.94 & 0.97 & 0.99 & 1.0 \\
\hline \multicolumn{7}{|l|}{ Positive } \\
\hline predictive value & 0.25 & 0.42 & 0.46 & 0.63 & 0.87 & 1.0 \\
\hline $\mathrm{LR}+*$ & 6.6 & 14.2 & 16.6 & 33 & 100 & $>100$ \\
\hline \multicolumn{7}{|l|}{ False positive } \\
\hline rate & 0.14 & 0.07 & 0.02 & 0.03 & 0.007 & 0 \\
\hline Accuracy & 0.85 & 0.93 & 0.94 & 0.97 & 0.99 & 1.0 \\
\hline
\end{tabular}

$* L R+=$ positive likelihood ratio. 


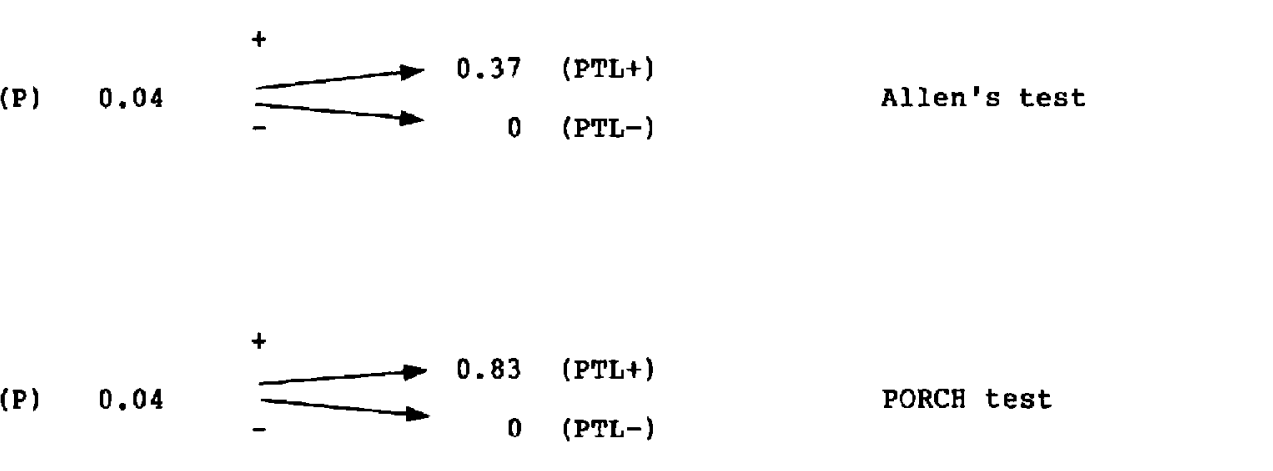

FIGURE I Diagnostic "Iree" for Allen's test and PORCH test. The patients cnter the tree at the left, with a pretest probability of an abnormal ulnar collateral circulation of $(\mathrm{P})$. If the test result is positive (abnormal) the probability rișcs to PTL + , the post-test probability of a positive (abnormal) result. If the result is negative (nomal) the probability falls to PTL-, the post-test probability of a negative (nomal) result.

utility. Further evidence for the reliability of Doppler ultrasound is also provided by the fact that the incidence of an abnormal ulnar collateral circulation of 4.8 per cent in this study (seven out of 144 patients) compares well with incidences between 2.1 per cent and 6 per cent reported earlier. ${ }^{7,8,10}$

Assessment of Allen's test demonstrates that it performed poorly in this study in spite of its high sensitivity and specificity. Its positive predictive value of 0.42 is similar to a previously reported value of $0.47 .^{22}$ Thus, an abnormal (positive) Allen's test would falsely indicate abnormality of the ulnar collateral circulation in about 60 per cent of hands based on our prevalence of disease. A negative predictive value of 1.0 suggests that 100 per cent of patients with a normal Allen's test will have a normal collateral circulation. Although not affected by sex or smoking, Allen's test has the disadvantage of being affected by age. Data collected in this study do not provide an explanation for this phenomenon. However, as the false positive rate was approximately six times higher in those over the age of 40 years as compared to those below 40 years, the use of Allen's test should probably be restricted to those below the age of 40 years.

Another source of confusion with Allen's test has been the matter of time. Previous studies have not documented the relationship between abnormality of the ulnar collateral circulation and revascularization times. Not surprisingly, the criteria used to classify patients as abnormal by Allen's test have been variable ranging from $5 \mathrm{sec}$ to 15 sec. ${ }^{6,11,12,24}$ The present study demonstrates that use of a revascularization time of less than $15 \mathrm{sec}$ with Allen's test is associated with a substantial decrease in its positive predictive value (Table IV). On the other hand, use of a revascularization time in excess of $15 \mathrm{sec}$ did not increase the positive predictive value by much. Thus, it is probably not advantageous to use times much above or below 15 sec with Allen's test when attempting to identify patients with an abnormal ulnar collateral circulation.

The PORCH test performed better than Allen's test at all conventional revascularization times and had the advantage of not being affected by age, sex or smoking. Therefore, it may usefully be applied in patients above or below 40 years. At a revascularization time of $15 \mathrm{sec}$ a positive predictive value of 0.87 for the PORCH test indicates that only 13 per cent of patients with an abnormal (positive) PORCH test will have a normal ulnar collateral circulation. Its negative predictive value of 1.0 indicates that all patients with a normal PORCH test will have a normal ulnar collateral cirçulation. Superior performance of the PORCH test is probably related to the intense reactive hyperaemia produced by total circulatory occlusion for two minutes.

The effect of performing either an Allen's test or the PORCH test using a "cut off" time of 15 seconds for both is clearly demonstrated in Figure 1. When the pretest probability (prevalence) of an abnormal ulnar collateral circulation is 0.048 (as found in this study), a positive (abnormal) Allen's test will only increase the post-test probability (PTL + , or post-test likelihood of a positive result) ${ }^{14}$ to 0.37 . On the other hand, a positive (abnormal) PORCH test increases PTL + to 0.83 . Both tests were equally effective in "ruling out" patients who did not have an abnormal ulnar collateral circulation as indicated by PTL (post-test likelihood of a negative result) ${ }^{14}$ values of zero. When the PORCH test was performed with a "cut-off" greater than $19 \mathrm{sec}$ as indicating an abnormal 


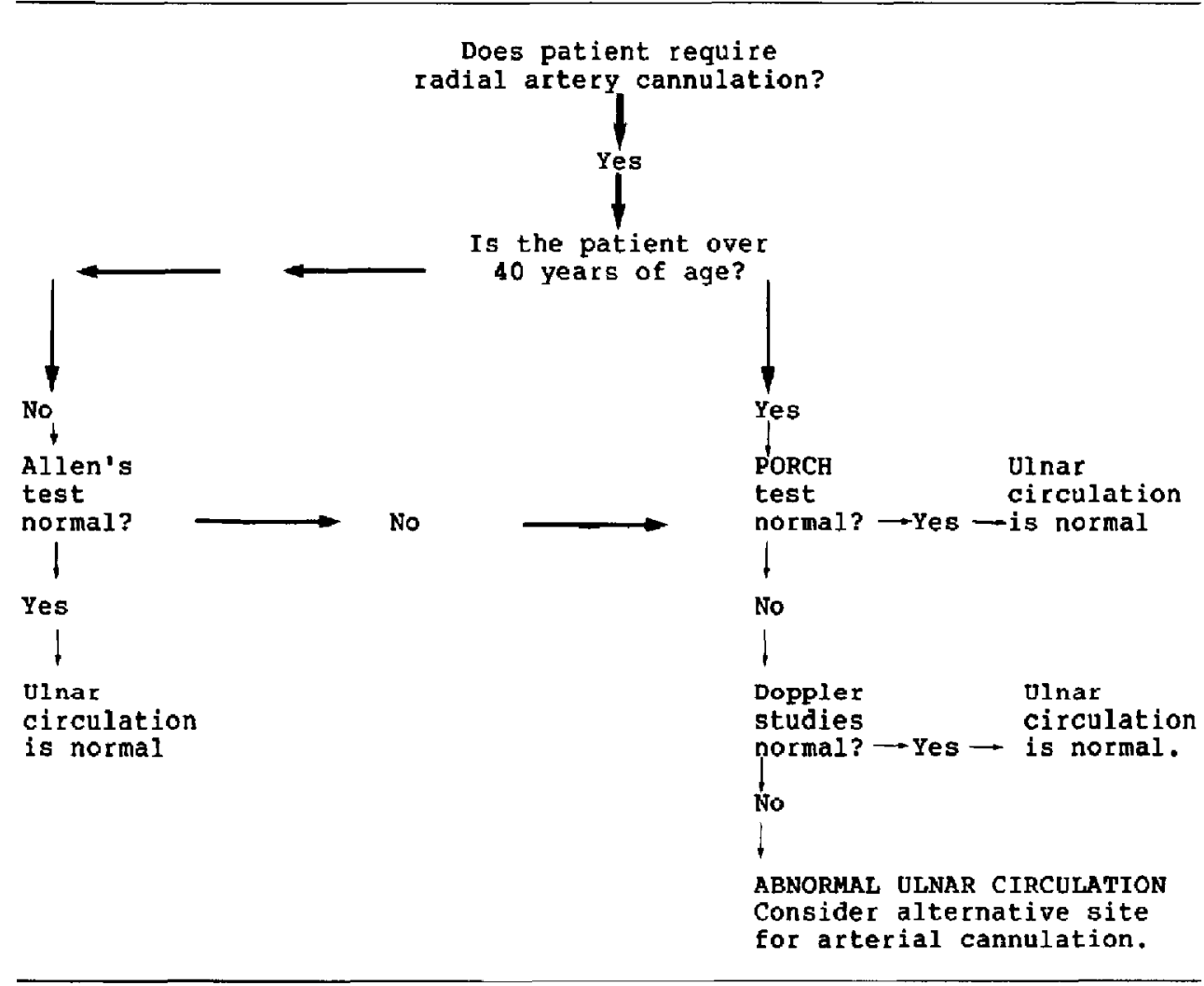

FIGURE 2 Suggesred flow chart for the management of patients requiring radial artery cannulation.

test, it was perfectly predictive of an abnormal ulnar collateral circulation. It should be noted that the attributes of the PORCH test are based on seven patients with an abnormal collateral circulation. Further assessments will therefore probably be necessary before these attributes can be stated with precision.

The results of this study have important clinical implications. First, Slogoff and Keat ${ }^{25}$ have suggested that Allen's test was not predictive of post-cannulation ischaemia in their study. However, all 16 of their patients with an abnormal Allen's test (greater than $15 \mathrm{sec}$ ) had normal radial artery flows on Doppler examination after decannulation. In addition, projection of a positive predictive value of 0.42 for Allen's test from the present study would suggest that at least 10 of these 16 patients had a normal ulnar collateral circulation. Not surprisingly, $\mathrm{Hug}^{2}$ reconmended continued use of an Allen's test until further evidence was forthcoming. The present study suggests that an Allen's test is only useful if it is normal (i.e., for "ruling out" patients who do not have an abnormal collateral circulation) and best applied to those under the age of 40 years. Secondly, although the value of an abnormal ulnar collateral circulation in predicting post-cannulation ischaemic damage has never been tested systematically, it is probably more important than some of the other known risk factors (for example cannula size and duration of cannulation). ${ }^{4}$ As such, it would be prudent to continue assessment of the collateral circulation in the hand prior to radial artery cannulation. ${ }^{26}$ The results of this study suggest that an optimal assessment of the ulnar collateral circulation will probably occur if a patient is managed as indicated in Figure 2. In such a flow chart, Allen's test is retained because of its simplicity and high negative predictive value. However, definitive decision- 
making is best made on the basis of the PORCH test or Doppler ultrasound. The PORCH test is quick and does not require special equipment. Doppler ultrasound, to be reliable, has to be applied with rigorous criteria (as employed in the present study) and becomes timeconsuming. In addition, it requires additional equipment that is not ordinarily available. An alternative and simpler strategy would be to discard the Allen's test and perform a PORCH test in all patients requiring radial artery cannulation.

In conclusion, data from a large double-blind study employing Doppler ultrasound as a reference, demonstrated that a postocclusive reactive circulatory hyperaemia (PORCH) test was superior to an Allen's test in idencifying patients with an abnomal ulnar collateral circulation.

\section{References}

1 Allen EV. Thromboangitis obliterans: methods of diagnosis of chronic acclusive arterial lesions distal to the wrist with illustrative cases. Am J Med Sci 1929; 178: 237-44.

2 Hug CC. Monitoning. In: Miller RD (Ed). Anesthesia. New York: Churchill Livingstone 1986: 411.

3 Ream $A K$. Monitoring techniques and concepts. In: Ream AK, Fogdal] RP (Eds). Acute cardiovascular management; anesthesia and intensive care. Philadelptia, JB Lippincott, 1982: 139.

4 Wilkins $R G$. Radial artery cannulation and ischaemic damage: a review. Anaesthesia 1985; 40: 896-9.

5 Husum B, Bershelsen P. Allen's test and systolic antrial pressure in the thumb. $\mathrm{Br} \mathrm{J}$ Anaesth $1981 ; 53: 635-7$

6 Kamienski $R W$, Barnes $R W$. Critique of the Allen's test for continuity of the palmar arch assessed by Doppler ultrasound. Surg Gynecol Obstet 1976; 142: 861-4.

7 Mozersky DS, Butkley CJ, Hagood CO, Capps WF, Dannemiller FJ. Ultrasonic evaluation of the palmar circulation - a useful adjunct to radial artery cannulation Am J Surg 1973; 126: 810-2.

8 Little JM, Zylstra PL, West J, May J. Circulatory patterns in the normal hand. Br J Surg 1973; 60: 652-5

9 Kaye W. Invasive monitoring techniques: arterial cannulation, bedside pulmonary artery catheterization and arterial puncture. Heart Lung 1983; 12: 395-425.

10 Gelberman RH, Blasingame JP. The timed Allen's test. J. Trauma 1981; $21: 477-9$.

11 Bedford RJ, Wollmam J. Complications of percutaneous radial artery cannulation. Anesthesiolugy 1973; 38: 228-36.

12 Davis FM. Stewart JM. Radial artery cannulation. A prospective study in patients undergoing cardiothoracic surgery. Br J Anacsth 1980; 52: 41-6.
13 Kaplan JA. Hemodynamic monitoring. Ir: Kaplan JA (Ed). Cardiac Anesthesia, New York, Grune and Stratton 1979: 71.

14 Sheps SB, Schechter MT. The assessment of diagnostic tests. JAMA 1984; 252: 2418-22.

15 Schechter $M T$, Sheps $S B$. Diagnostic testing revisited: pathways through uncertainty. Can Mcd Assoc J, 1985; 13: 755-60.

16 Department of Clinical Epidemiology and Biostatistics, McMaster University. Clinical disagreement: $I$. How often it occurs and why. Can Med Assoc J 1980; 123; 499-503.

17 Simm $M H$, Hardman $J$, Slaney $G$. The relevance of prebypass pedal arch assessment. Br J Surg 1984; 71 : $381-6$.

18 Roedersheimer $L R$, Feins $R$, Green $R M$. Doppler evaluation of the pedal arch. Am J Surg 1981; 142: 601-4.

19 Campbell WB. Fletcher EL, Hands $L$. Assessment of the distal lower limb arteries: a comparison of arteriography and Doppler ultrasound. Ann R Coll Surg Engl 1986; 68: 37-9.

20. Balas $P$, Katsogiannis A, Katsiotis $P$, Karaitianos $J$. Comparative study of evaluation of digital arterial circulation by Doppler ultrasonic tracing and hand arteriography. J Cardiovas Surg 1980; 21: 455-62.

21 Coleman, SS, Anson BJ. Artcrial pancrns in the hand based upon a study of 650 specimens. Surg Gyneco! Obste1 1961; 113: 409-24.

22 Mangano DT, Hickey RF. Ischemic injury following uncomplicated radial artery catheterization. Anesth Analg $1979 ; 58: 55-7$.

23. Husum B, Berthelsen P. Allen's test and systolic arterial pressure in the thumb. Br J Anaesth 198I; 53: 635-7.

24 Bedford $R F$. Radial artery function following percutaneous cannulation with 18 and 20 gauge catheters. Anesthesiology 1977; 47: 37-9.

25 Slogoff S, Keats AS, Arlund C. On the safety of radial artery cannulution. Anesthesiology 1983; 59:42-7.

26 Bedford RF. Invasive Blood Pressure Monitoring. I $m$ : Blitt $\mathrm{CD}$ (Ed). Monitoring in Anesthesia and Critical Care Medicine, New York, Churchill Livingstone 1985: 41. 
Résumé

Celle étude prospertive à double insu compare l' évaluation au Doppier de la circulation cubitale avec le test d'Allen et le test de (PORCH) d' hyperémie réactive postocclusive chez 144 parients (288 mains). Le test de PORCH implique l'inflation du sphymomanomèrre appliqué sur ie bras à une pression supra sustolique (+ $50 \mathrm{mmhg}$ ) pour deur minutes. Avant le dégonftement du sphygmomanomètre les artères radiale et cubitale sont occluses au niveau du poigner. Le brassard est par la suize dégonflé et l'on attend 15 secondes afin de permettre la restauration du flot sanguin au poignet. La compression de l'artère cubitale est maintenant relâchée et le temps do revascularisation mesuré. Cinquante-huit pour cent des mains avant présenté un test d'Allen anormal avaient une circulation collatérale cubitale normaie. Les résultats des tests a'Allen n'étaient pas significativement affectés par le sexe des patients ou le tabogisme $(p>0.1)$ mais il $y$ arait une différence significative ( $p=0.001)$ avec les taux de lest faussement positifs entre les parients âgés de plus que 40 ans (0.2) et ceux ágés de moins que 40 ans $(0,03)$. Les rêsultats des tests de PORCH n'étaient pas significanivement affectés par l'âge des patients, leur sexe ou leur tabagisme $(p>0.1)$. Avec un temps de revascularisation de 19 secondes pris numme point de repère pour une anomalie dans ia circulation collatérale, le test de PORCH, contrairement au test d'Allen, pouvait prédire parfairement une circulation collatérale cubitale anormale er ne présentait pas de faux positif.r. 